\title{
Non-conventional dysplastic subtypes in inflammatory bowel disease: a review of their diagnostic characteristics and potential clinical implications
}

\author{
Won-Tak Choi \\ Department of Pathology, University of California at San Francisco, San Francisco, CA, USA
}

\begin{abstract}
The early detection and grading of dysplasia is the current standard of care to minimize mortality from colorectal cancer (CRC) in patients with inflammatory bowel disease. With the development of advanced endoscopic resection techniques, colectomy is now reserved for patients with invisible/flat dysplasia (either high-grade [HGD] or multifocal low-grade dysplasia) or endoscopically unresectable lesions. Although most pathologists are familiar with the morphologic criteria of conventional (intestinal type) dysplasia, the most well-recognized form of dysplasia, an increasing number of diagnostic material has led to the recognition of several different morphologic patterns of epithelial dysplasia. The term "non-conventional" dysplasia has been coined to describe these changes, but to date, the recognition and full appreciation of these novel forms of dysplasia by practicing pathologists is uneven. The recognition of these non-conventional subtypes is becoming increasingly important, as some of them appear to have a higher risk of developing HGD or $\mathrm{CRC}$ than conventional dysplasia or sporadic adenomas. This review describes the morphologic characteristics of all seven non-conventional subtypes that have been reported to date as well as our current understanding of their clinicopathologic and molecular features that distinguish them from conventional dysplasia or sporadic adenomas.
\end{abstract}

Key Words: Colorectal neoplasm; Dysplasia; Inflammatory bowel disease; Non-conventional

Received: January 15, 2021 Accepted: February 17, 2021

Corresponding Author: Won-Tak Choi, MD, PhD, Department of Pathology, University of California at San Francisco, 505 Parnassus Avenue, M552, Box 0102, San Francisco, CA 94143, USA

Tel: +1-415-353-9533, Fax: +1-415-353-1200, E-mail:Won-Tak.Choi@ucsf.edu

Although pathologists have a good grasp of the morphologic criteria of conventional (intestinal type) dysplasia, several unfamiliar morphologic patterns of epithelial dysplasia have been recently described in inflammatory bowel disease (IBD). They are collectively referred to as "non-conventional" dysplasia, and there are at least seven subtypes that have been reported to date. This review summarizes their morphologic criteria as well as clinicopathologic and molecular features that distinguish them from conventional dysplasia or sporadic adenomas. The review is divided into three major parts: (1) clinical importance and management of invisible/flat dysplasia, (2) potential significance of non-conventional dysplasia, and (3) subtypes of non-conventional dysplasia- (a) hypermucinous dysplasia, (b) crypt cell dysplasia, (c) dysplasia with increased Paneth cell differentiation, (d) goblet cell deficient dysplasia, and (e) serrated dysplasia, including sessile serrated lesion (SSL)-like dysplasia, traditional serrated adenoma (TSA)-like dysplasia, and serrated dysplasia, not otherwise specified (NOS).

\section{CLINICAL IMPORTANCE AND MANAGEMENT OF INVISIBLE/FLAT DYSPLASIA}

IBD is a well-established risk factor for the development of dysplasia and/or colorectal cancer (CRC) [1-5]. The risk of CRC is similar in both ulcerative colitis (UC) and Crohn's disease [3], but younger age, male gender, longer disease duration, and primary sclerosing cholangitis (PSC) are often associated with a higher risk of developing dysplasia and/or CRC [4,6-8]. Surveillance colonoscopy is typically initiated at eight years after IBD diagnosis to detect pre-invasive, dysplastic lesions to reduce mortality from CRC [9-13].

Traditionally, the detection of IBD-related dysplasia has re- 
lied on targeted sampling of endoscopically visible lesions as well as extensive random biopsies [14,15]. Also, it was thought to be important to distinguish IBD-related polypoid dysplasia (dysplasia-associated lesion or mass) from a sporadic adenoma, because the former was an indication for colectomy due to the high perceived probability of associated CRC, while the latter was usually treated by simple polypectomy [16]. However, along with advances in both endoscopic visualization and resection capability, it has become clear that the vast majority of IBD-related dysplastic lesions are endoscopically visible $[17,18]$ and can be safely managed with endoscopic resection [19-22]. In fact, a systemic review of 10 studies reported $0.5 \%$ annual incidence of CRC in IBD patients with endoscopically resectable visible/polypoid dysplasia [19]. In light of these findings, the recent SCENIC (Surveillance for Colorectal Endoscopic Neoplasia Detection and Management in Inflammatory Bowel Disease Patients: International Consensus Recommendations) guidelines recommend that all visible/polypoid dysplastic lesions in IBD patients be managed with endoscopic resection (Fig. 1A), while invisible/flat dysplasia, particularly high-grade dysplasia (HGD), often necessitates colectomy (Fig. 1B) [13]. Indeed, sev-
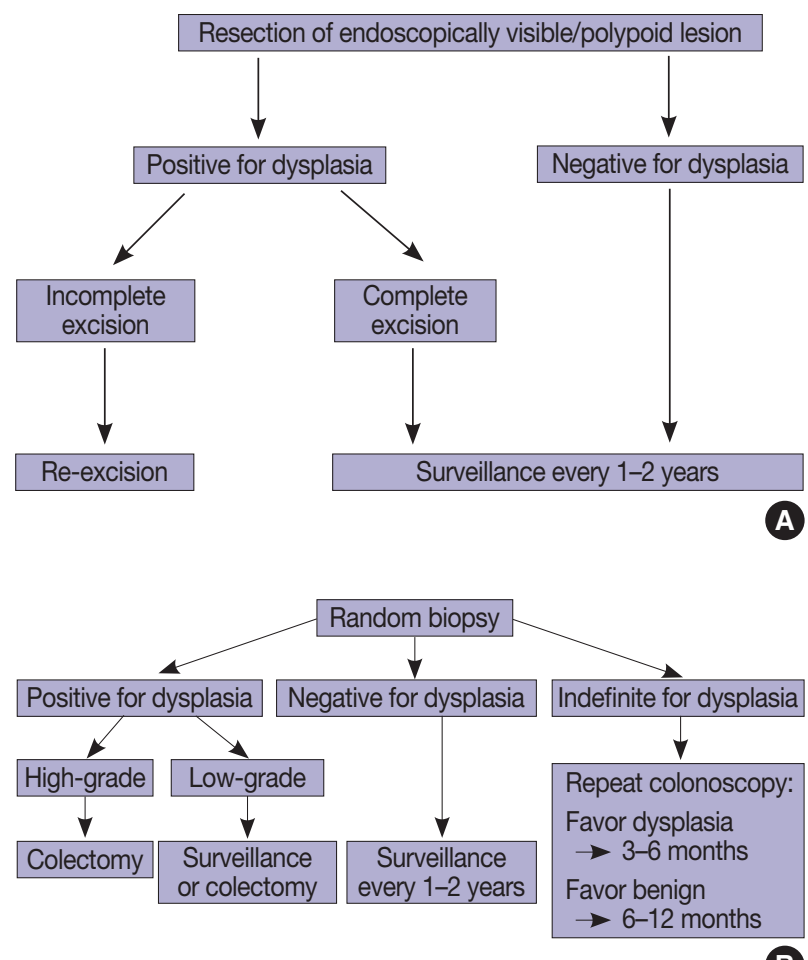

Fig. 1. Algorithms for management of endoscopically visible/polypoid dysplasia (A) versus invisible/flat dysplasia (B) in inflammatory bowel disease patients undergoing surveillance colonoscopies. eral studies reported high rates of synchronous CRC (50\%-67\%) in colectomy specimens following a diagnosis of invisible/flat HGD [12,23-25]. Although the management of invisible/flat low-grade dysplasia (LGD) remains controversial due to its highly variable progression rates to advanced neoplasia (HGD or CRC) ranging from $0 \%$ to $>50 \%$ [23,26-37], colectomy is usually recommended for multifocal invisible/flat LGD [13].

There is evidence that IBD-related invisible/flat dysplasia may have different molecular features compared with visible/ polypoid dysplasia. For instance, the frequency of large-scale chromosomal alterations resulting in aneuploidy as detected by DNA flow cytometry is significantly higher in invisible/flat dysplasia (41\% for invisible/flat LGD and $93 \%$ for invisible/flat HGD) [37] than in low-grade conventional dysplasia (8\%) or sporadic adenomas (9\%) [38]. Likewise, using next-generation sequencing, Wanders et al. [39] reported that IBD-related dysplastic lesions that are often invisible or flat have more DNA copy number alterations (average number of gains and losses of 4.3 and 3.2, respectively) than sporadic adenomas (1.5 and 0.5, respectively). Overall, these findings indicate that invisible/flat dysplasia has more chromosomal instability than conventional dysplasia or sporadic adenomas, which may explain its frequent association with advanced neoplasia. In support of this, we also demonstrated that the presence of aneuploidy in the setting of invisible/flat LGD is a significant risk factor for subsequent detection of advanced neoplasia with the univariate and multivariate hazard ratios of $5.3(\mathrm{p}=.006)$ and $4.5(\mathrm{p}=.040)$, respectively [37].

\section{POTENTIAL SIGNIFICANCE OF NON-CONVENTIONAL DYSPLASIA}

Most of the literature on IBD-related dysplasia refers to conventional (or intestinal type) dysplasia, the most common form of dysplasia. Conventional dysplasia is defined by histologic features fundamentally identical to those of sporadic adenomas (Fig. 2A). In fact, the Riddell grading system proposed in 1983 for assessment of epithelial dysplasia in IBD mostly pertains to conventional dysplasia and categorizes IBD-related dysplasia into either LGD or HGD based on the degree of cytologic and/ or architectural atypia [40]. LGD is characterized by crowded, elongated, hyperchromatic nuclei that are confined to the basal half of the cytoplasm, involving both crypts and surface epithelial cells (Fig. 2A), whereas HGD shows more severe cytologic (i.e., enlarged, rounder nuclei, pleomorphism, and loss of nuclear polarity) and/or architectural atypia (such as back-to-back glands 

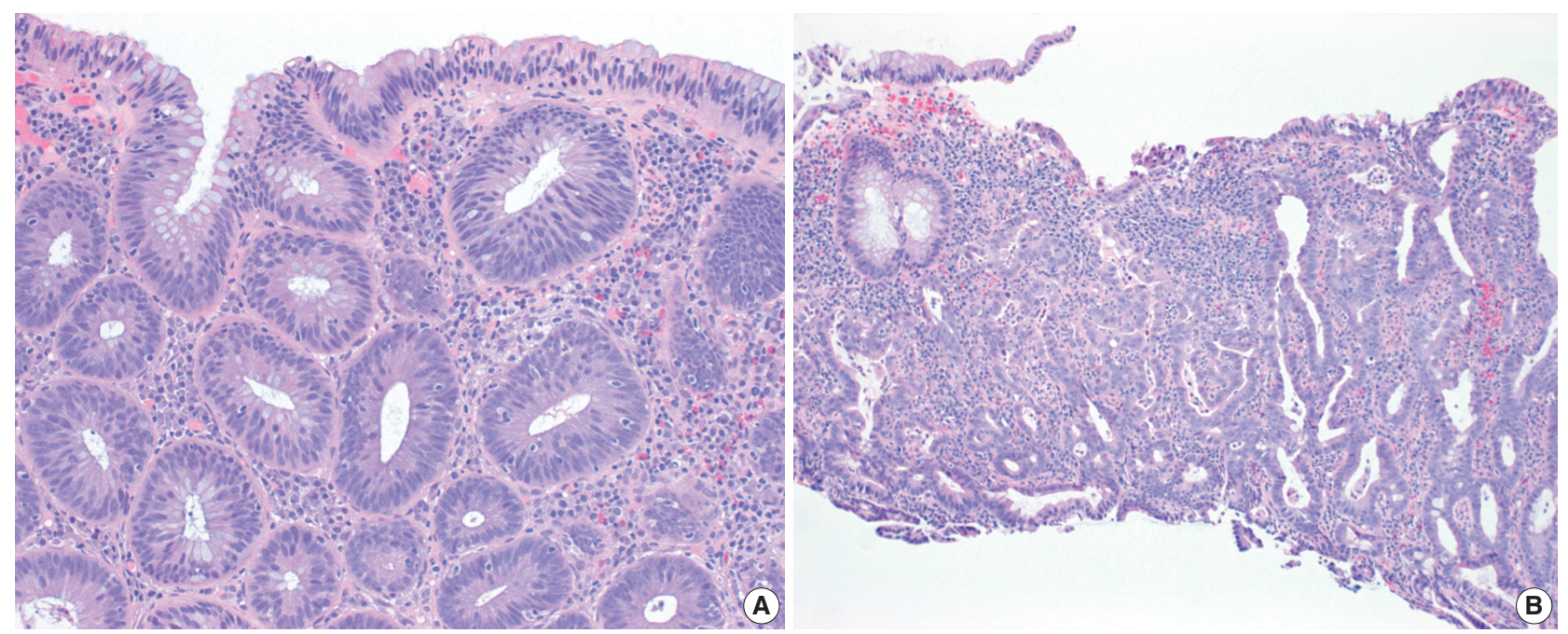

Fig. 2. Conventional dysplasia. (A) Invisible/flat low-grade dysplasia shows a tubular architecture lined by crowded, pencillate, hyperchromatic nuclei involving both crypts and surface epithelial cells. While goblet cells are reduced, they are easily identified. (B) Invisible/flat highgrade dysplasia shows severe cytologic and architectural atypia.

and cribriform formation) (Fig. 2B) [40]. Goblet cells may be reduced, but they are easily identified. Although a diagnosis of HGD does not require surface involvement, pathologists are accustomed to diagnosing dysplasia—including HGD—when dysplastic cells involve the surface epithelium. If nuclear atypia is limited to the crypt base without surface involvement, a diagnosis of "indefinite for dysplasia (IND)" or "reactive atypia" is often rendered, largely based on the assumption that true dysplasia does not maintain the capacity for maturation, as dysplastic cells migrate toward the surface epithelium.

Although pathologists have a good grasp of the morphologic criteria of conventional dysplasia, several unfamiliar morphologic patterns of dysplasia (collectively known as "non-conventional" dysplasia) have been recently described in IBD. There are at least seven subtypes, including (1) hypermucinous dysplasia; (2) crypt cell dysplasia; (3) dysplasia with increased Paneth cell differentiation; (4) goblet cell deficient dysplasia; (5) SSL-like dysplasia; (6) TSA-like dysplasia; and (7) serrated dysplasia NOS [38,41-43]. Although their clinicopathologic and molecular features are not fully characterized, in part due to the rarity of these subtypes and the likelihood that they are under-recognized, the recognition of these non-conventional subtypes is becoming increasingly important, as they often present as invisible/flat lesions, and at least some of them appear to have a higher malignant potential than conventional dysplasia or sporadic adenomas.

In this regard, we previously reported that non-conventional dysplasia, as a group, is common in a cohort of 58 IBD patients with CRC, detected in 45\% [41]. Although it was often associ- ated with conventional dysplasia, more commonly in the same colonic segment, up to $21 \%$ of the patients had non-conventional dysplasia only. Interestingly, despite its low-grade morphology ( $81 \%$ vs. $37 \%$ for conventional dysplasia; $\mathrm{p}=.003$ ), non-conventional dysplasia was found in the same colonic segment as CRC or immediately adjacent to the $\mathrm{CRC}$ at a rate $(85 \%)$ similar to conventional dysplasia (96\%). Furthermore, CRC occurring in patients with non-conventional dysplasia only was more likely to be high-grade (poorly differentiated; 36\%) than CRC that occurred in association with conventional dysplasia $(10 \%)(\mathrm{p}=.026)$. Taken together, these findings, for the first time, raised the possibility that non-conventional dysplasia may be associated with an increased risk for advanced neoplasia compared with conventional dysplasia.

In support of this argument, we recently reported that nonconventional dysplasia (38\%) is more frequently associated with advanced neoplasia than conventional dysplasia $(19 \%)(\mathrm{p}<.001)$ [38]. Notably, non-conventional dysplasia with low-grade morphology had a significantly higher rate of aneuploidy (46\%) than low-grade conventional dysplasia $(8 \%, \mathrm{p}=.002)$ or sporadic adenomas $(9 \%, \mathrm{p}=.037)$. Also, non-conventional dysplasia ( $41 \%)$ was more likely to present as invisible/flat dysplasia than conventional dysplasia (18\%) ( $\mathrm{p}<.001)$, suggesting that a current move towards performing only targeted biopsies in IBD patients [44] may miss some of these high-risk, non-conventional dysplastic lesions, and that IBD patients may potentially benefit from random biopsies in addition to targeted sampling of visible lesions.

In another larger multicenter study of 126 additional cases of 
non-conventional dysplasia (including 55 hypermucinous, 45 crypt cell, and 26 goblet cell deficient dysplastic lesions), we demonstrated that $66 \%$ of the non-conventional dysplastic lesions presented as invisible/flat lesions (vs. $18 \%$ for conventional dysplasia; $\mathrm{p}<.001$ ), and that $60 \%$ of the lesions were associated with subsequent detection of advanced neoplasia at the site of previous biopsy or in the same colonic segment within a mean follow-up time of 12 months (vs. 10\% for conventional dysplasia; $\mathrm{p}<.001$ ) (unpublished results). Overall, these findings support that non-conventional dysplasia has distinct clinicopathologic, molecular, and risk profiles compared with conventional dysplasia, underscoring the importance of recognizing non-conventional dysplasia and recommending its complete removal and/ or careful follow-up.

\section{SUBTYPES OF NON-CONVENTIONAL DYSPLASIA}

\section{Hypermucinous dysplasia}

Hypermucinous dysplasia represents approximately $2 \%$ of all dysplastic lesions in IBD patients (Table 1) [38]. Most patients have a long history of IBD with a mean duration of 23 years. It is predominantly found in UC patients (86\%) who often have a concurrent history of PSC (29\%). Although the majority of hypermucinous dysplastic lesions have a polypoid endoscopic appearance with a mean size of $2.1 \mathrm{~cm}$ [38], up to $42 \%$ are endoscopically invisible or flat (unpublished results). Hypermucinous dysplasia shows a predilection for the left colon (57\%).

Morphologically, hypermucinous dysplasia most often demonstrates a tubulovillous/villous architecture lined by tall, prominent mucinous cells representing $>50 \%$ of the lesion (Fig. 3A, B) $[38,41,43]$. Although low-grade dysplastic features are usually present in crypts, the degree of atypia tends to decrease towards the surface epithelium due to prominent mucinous differentiation, so one must be careful not to miss hypermucinous dysplasia when evaluating superficial fragments with hypermucinous features but without significant nuclear atypia (Fig. 3B). The presence of high-grade nuclear features is relatively uncommon (29\%). Hypermucinous dysplasia can present either as a 'pure type' or a 'mixed type' with either conventional or another nonconventional subtype (most often with a serrated subtype) [41]. However, to be categorized as the mixed type, the hypermucinous component should represent $>50 \%$ of the lesion.

There is increasing evidence that hypermucinous dysplasia may be a marker of increased risk for advanced neoplasia. First, hypermucinous dysplasia was the most common non-conven- tional subtype ( $42 \%$ ) found in a cohort of 58 IBD patients with CRC [41]. Second, a significant proportion of hypermucinous dysplastic lesions (57\%) were associated with advanced neoplasia [38]. In another study, we demonstrated that 19 (49\%) of 39 low-grade hypermucinous dysplastic lesions were correlated with subsequent detection of HGD $(n=9,23 \%)$ or adenocarcinoma $(n=10,26 \%)$ at the site of previous biopsy or in the same colonic segment within a mean follow-up time of 11 months (unpublished results). Third, hypermucinous dysplasia, even without cytologic atypia, has been shown to have a higher rate of KRAS mutations $(61 \%)$ than conventional LGD $(4 \%, \mathrm{p}<.001)$ or HGD (29\%, p > .05) [45]. Similarly, we reported that the frequency of aneuploidy in low-grade hypermucinous dysplasia $(80 \%)$ is significantly higher than that of low-grade conventional dysplasia $(8 \%)$ or sporadic adenomas $(9 \%)(\mathrm{p}<.001)$ [38]. In fact, its rate of aneuploidy ( $80 \%)$ is similar to that of invisible/ flat HGD (93\%) [37]. Overall, these results indicate that despite its low-grade morphology, hypermucinous dysplasia shares similar molecular features with conventional HGD, suggesting that it may represent at least a high-risk low-grade lesion, if not already HGD. These findings also suggest that KRAS mutations and/or aneuploidy may contribute to the development of tubulovillous/villous growth, larger size, and/or higher biologic grade in hypermucinous dysplasia [46]. Similar to conventional dysplasia, hypermucinous dysplasia most likely develops via the chromosomal instability pathway involving multiple genetic mutations (including KRAS, TP53, and APC genes) and altered regulation of Wnt/ $\beta$-catenin pathway, as well as aneuploidy [47-50].

\section{Crypt cell dysplasia}

Crypt cell dysplasia accounts for approximately $4 \%$ of all dysplastic lesions in IBD patients (Table 1) [38], but it is likely an under-diagnosed entity. Most patients have a long history of IBD (mean duration: 15 years) and often have a concurrent history of PSC $(43 \%)$ [38,42]. It is predominantly found in UC patients and shows a propensity for the left colon (79\%). It exclusively presents as an invisible/flat lesion. When endoscopically visible, it has been described as "mild inflammation," "edema," "erythema," "friable," or "scarring" [42].

Histologically, crypt cell dysplasia is characterized by mildly enlarged, round-to-oval or slightly irregular, crowded, hyperchromatic nuclei limited to the crypt base without surface involvement or significant architectural atypia (Fig. 3C, D) [38,42,43]. Increased mitoses at the base of crypts are common (Fig. 3D). Although a few scattered cells may show more than mild nuclear enlargement and/or focal loss of nuclear polarity, there is no 


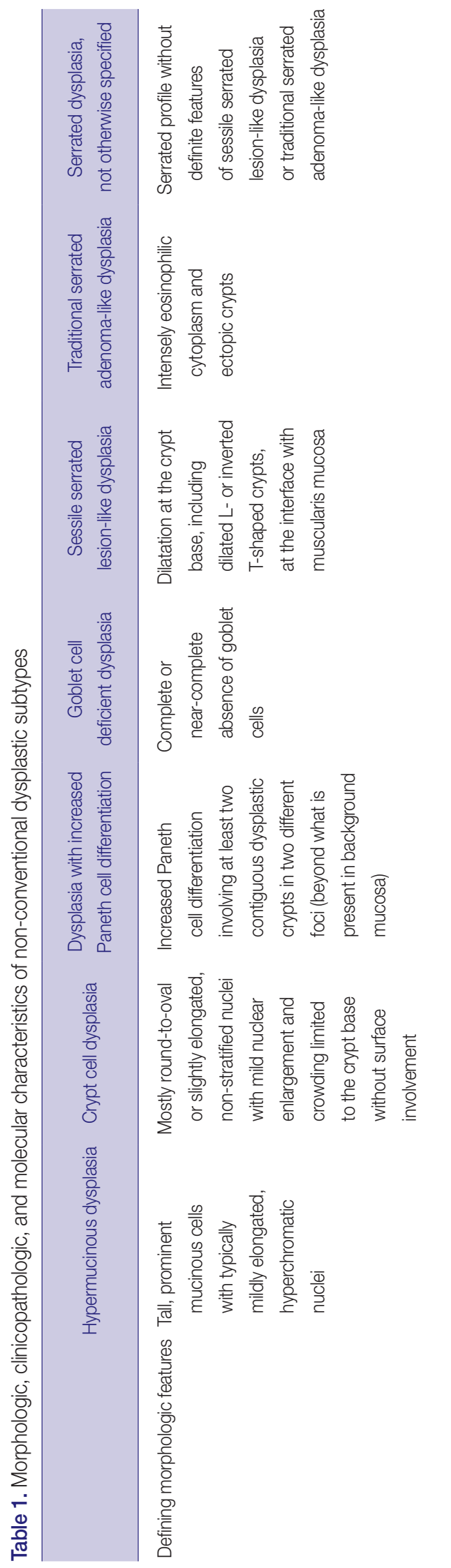

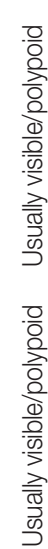

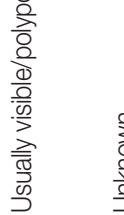

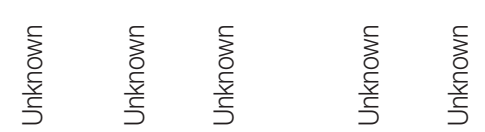

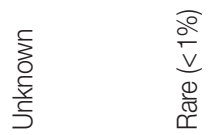

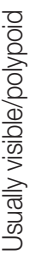

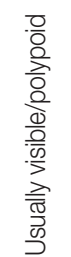

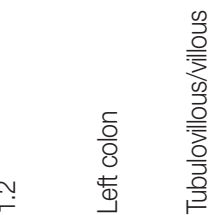<smiles>COCCO</smiles>

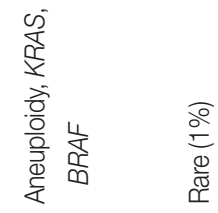

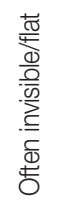

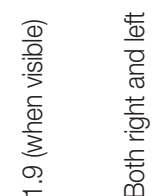

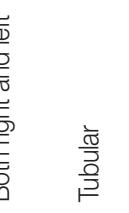

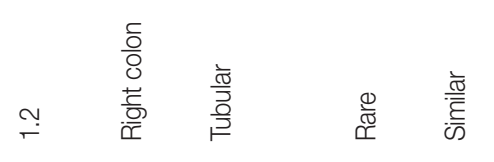

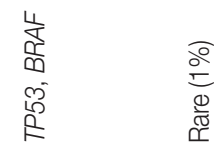

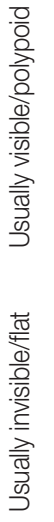

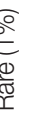

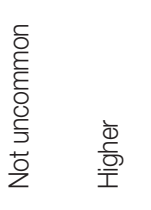

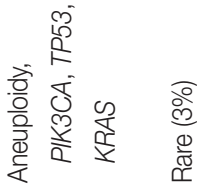

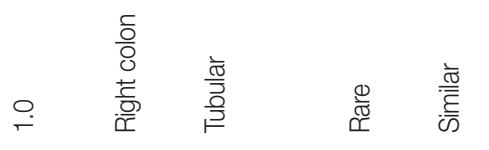

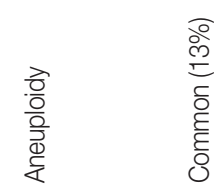

$\begin{array}{ll}\frac{0}{0} & \\ \frac{0}{0} & \frac{0}{0} \\ \frac{0}{0} & \frac{0}{0} \\ \frac{0}{0} & 0 \\ \frac{0}{2} & \frac{1}{4}\end{array}$

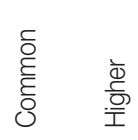

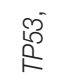

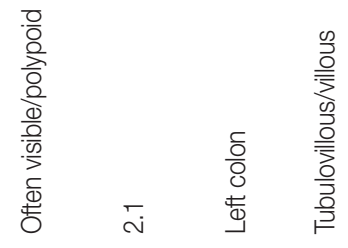

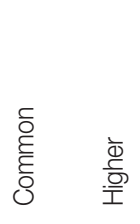

亭

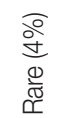

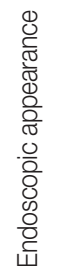

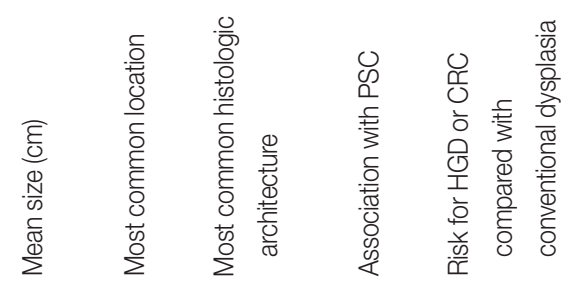

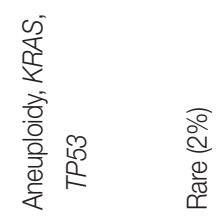



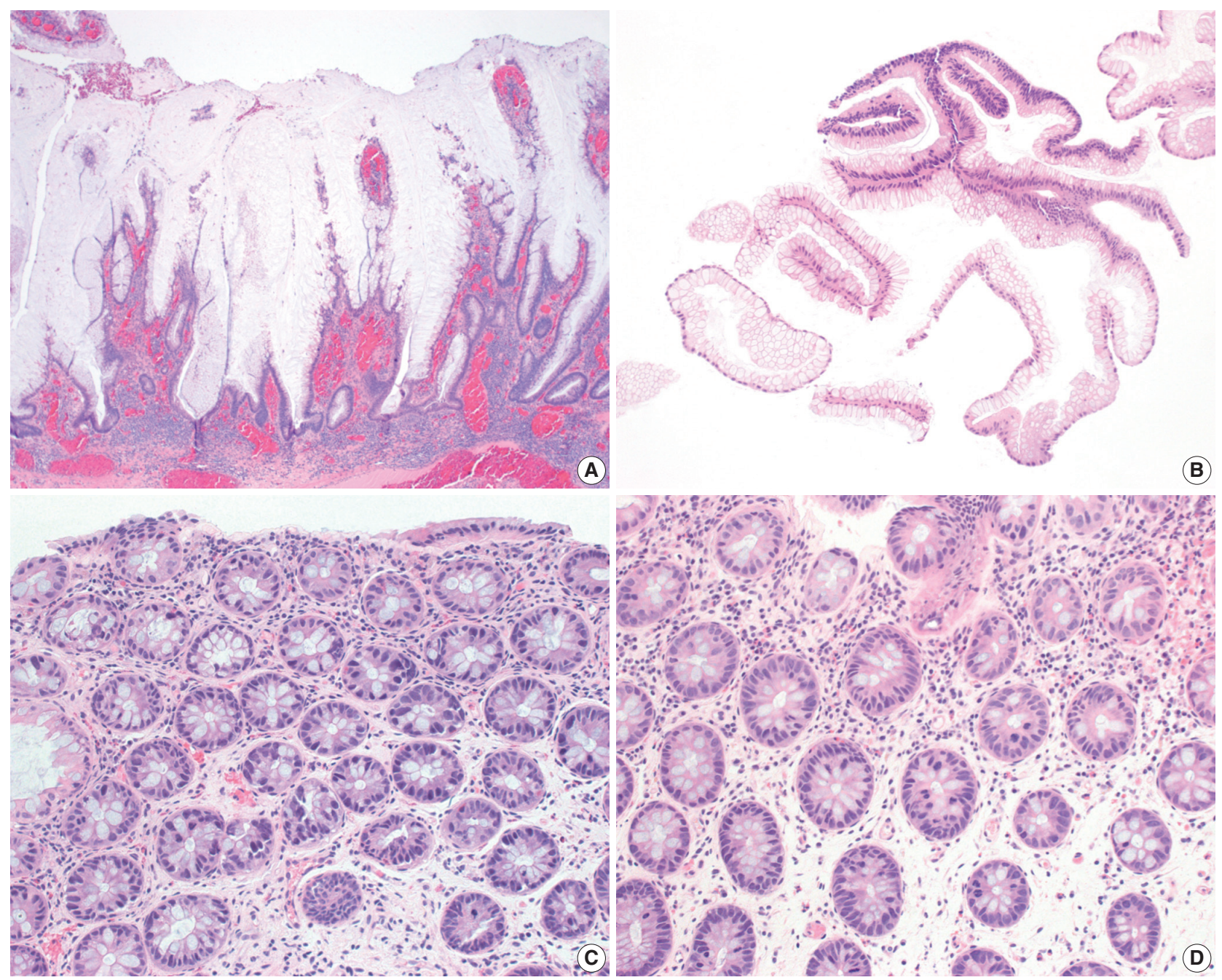

Fig. 3. Hypermucinous and crypt cell dysplasias. (A) Hypermucinous dysplasia demonstrates a tubulovillous lesion with mild nuclear atypia and prominent mucinous differentiation. (B) Superficial fragments of hypermucinous dysplasia show prominent mucinous cells with minimal to no nuclear atypia. (C, D) Crypt cell dysplasia is characterized by mostly round-to-oval or slightly elongated, hyperchromatic nuclei with mild nuclear enlargement and crowding limited to the crypt base without surface involvement. Increased mitoses are present (D).

unequivocal evidence of HGD. To avoid confusion with reactive changes, significant neutrophilic inflammation and/or ulceration should be absent. Immunohistochemical staining for $\mathrm{p} 53$ could be potentially useful to distinguish crypt cell dysplasia from reactive changes, as strong and diffuse $\mathrm{p} 53$ nuclear staining has been reported in up to $63 \%$ of crypt cell dysplastic lesions [42].

Similar to hypermucinous dysplasia, crypt cell dysplasia is considered a high-risk marker for advanced neoplasia. In support of this, we reported that six of seven patients (86\%) with crypt cell dysplasia developed HGD ( $\mathrm{n}=4,57 \%)$ or CRC ( $\mathrm{n}=2$, $29 \%)$ in the same colonic segment within a mean follow-up time of 27 months [38,42]. Notably, all 14 biopsies with crypt cell dysplasia from the seven patients demonstrated aneuploidy [42]. This is consistent with our previous finding that invisible/ flat dysplasia in IBD patients is characterized by the high rate of aneuploidy ( $41 \%$ for invisible/flat LGD and $93 \%$ for invisible/flat HGD) [37]. Taken together, these findings indicate that crypt cell dysplasia likely represents at least high-risk LGD, if not already HGD. Other investigators also reported that TP53 (43\%) and KRAS (14\%) mutations are common in crypt cell dysplasia, further confirming its dysplastic nature [47]. Of note, these results are very similar to what has been described in Barrett's esophagus-related "crypt dysplasia," which showed similar molecular alterations (i.e., aneuploidy and TP53 mutations) that are normally found in traditional dysplasia with surface involvement [51].

In practice, it may be difficult to diagnose and/or grade crypt cell dysplasia in a consistent manner on histologic grounds alone. 
In fact, we previously reported a poor interobserver agreement in the diagnosis and/or grading of crypt cell dysplasia [42]. Even though the majority of pathologists recognized its atypical morphology and diagnosed as IND, LGD, or HGD in $83 \%$ of their readings, a diagnosis of IND was made in $50 \%$ rather than either LGD (13\%) or HGD (19\%). As such, in challenging situations, we recommend that pathologists use the diagnostic term "crypt cell atypia" to describe similar changes and recommend a repeat colonoscopy within 3-6 months. If there is significant neutrophilic inflammation and/or ulceration in the areas of cytologic atypia, it may be more appropriate to make a diagnosis of IND and suggest a repeat colonoscopy within 3-6 months (Fig. 1B).

\section{Dysplasia with increased Paneth cell differentiation}

Dysplasia with increased Paneth cell differentiation is a common non-conventional subtype accounting for $51 \%$ of nonconventional dysplastic lesions and $13 \%$ of all dysplastic lesions in IBD patients (Table 1) [38]. The majority of affected patients have a long history of IBD (mean duration: 17 years), but a concurrent history of PSC is rare (9\%). Dysplasia with increased Paneth cell differentiation most often presents as a polypoid lesion $(70 \%)$ with a mean size of $1 \mathrm{~cm}$. The right colon is most frequently involved ( $45 \%$ ), and there appears to be a strong association with male sex (82\%).

The defining histologic feature of dysplasia with increased Paneth cell differentiation is increased Paneth cell differentiation involving at least two contiguous dysplastic crypts in two different foci (beyond what is present in background mucosa) (Fig. 4A, B) [38,41,43]. It usually demonstrates a tubular architecture mostly lined by elongated, hyperchromatic nuclei involving both crypts and surface epithelial cells. Goblet cells may be reduced, but they are not absent or nearly-absent. Although scattered Paneth cells may be present in other dysplastic subtypes, they are not present in multiple crypts and in multiple foci as in dysplasia with increased Paneth cell differentiation, and the same degree of Paneth cell differentiation is always present in adjacent, non-dysplastic mucosa.

Unlike hypermucinous and crypt cell dysplasias, increased Paneth cell differentiation may be a marker of lower-risk lesions. In favor of this, we previously demonstrated that the risk of harboring advanced neoplasia in dysplasia with increased Paneth cell differentiation (15\%) is compatible to that of conventional dysplasia $(19 \%)(\mathrm{p}=.523)$. Also, the rate of aneuploidy in lowgrade lesions (12\%) is similar to that of low-grade conventional dysplasia $(8 \%, \mathrm{p}=0.715)$ or sporadic adenomas $(9 \%, \mathrm{p}=.823)$ [38]. These results are in agreement with our previous finding that dysplasia with increased Paneth cell differentiation was a rare non-conventional subtype (11\%) found in a cohort of 58 IBD patients with CRC [41].

Interestingly, sporadic Paneth cell-containing adenomas have been described in the literature with the reported frequency of $0.2 \%$ to $39 \%$ [52-55]. Even though these earlier studies defined the presence of even one Paneth cell as histologic evidence of increased Paneth cell differentiation, sporadic Paneth cell-containing adenomas appear to share similar clinicopathologic features with their IBD-related counterpart. For instance, Pai et al. [55] reported that sporadic Paneth cell-containing adenomas are more likely to occur in the right colon $(85 \%$ vs. $56 \%$ for nonPaneth cell-containing adenomas; $\mathrm{p}=.006$ ) and in male individuals (89\% vs. $56 \%$ for non-Paneth cell-containing adenomas; $\mathrm{p}=.002)$. Also, Mahon et al. [53] demonstrated that sporadic Paneth cell-containing adenomas in the proximal $(\mathrm{p}=.157)$ and distal colon $(\mathrm{p}=.797)$ are not significantly associated with subsequent detection of CRC, compared with non-Paneth cell-containing adenomas.

\section{Goblet cell deficient dysplasia}

Goblet cell deficient dysplasia represents approximately 3\% of all dysplastic lesions in IBD patients (Table 1) [38]. Most patients have a long history of IBD (mean duration: 17 years). Although a concurrent history of PSC is not uncommon (14\%), it appears to be not as frequent as in patients with crypt cell dysplasia (43\%) or hypermucinous dysplasia (29\%). Goblet cell deficient dysplasia is often endoscopically invisible or flat (40\%), but when endoscopically visible, it usually presents as a large polypoid lesion with a mean size of $1.9 \mathrm{~cm}$. It is equally common in both right and left colon ( $40 \%$ each).

Morphologically, goblet cell deficient dysplasia is defined by a complete or near-complete absence of goblet cells, often leading to intensely eosinophilic cytoplasm (Fig. 4C, D) [38,41,43]. It predominantly shows a tubular architecture with low-grade dysplastic features involving both crypts and surface epithelial cells. However, up to $40 \%$ of goblet cell deficient dysplastic lesions may demonstrate HGD at diagnosis. Eosinophilic luminal secretion is another common histologic feature of goblet cell deficient dysplasia (Fig. 4C).

Similar to hypermucinous and crypt cell dysplasias, goblet cell deficient dysplasia may be another high-risk marker for advanced neoplasia. In support of this, as noted above, $40 \%$ of goblet cell deficient dysplastic lesions were associated with advanced neoplasia [38]. In another study, we demonstrated that $10(59 \%)$ of 17 low-grade goblet cell deficient dysplastic lesions were corre- 

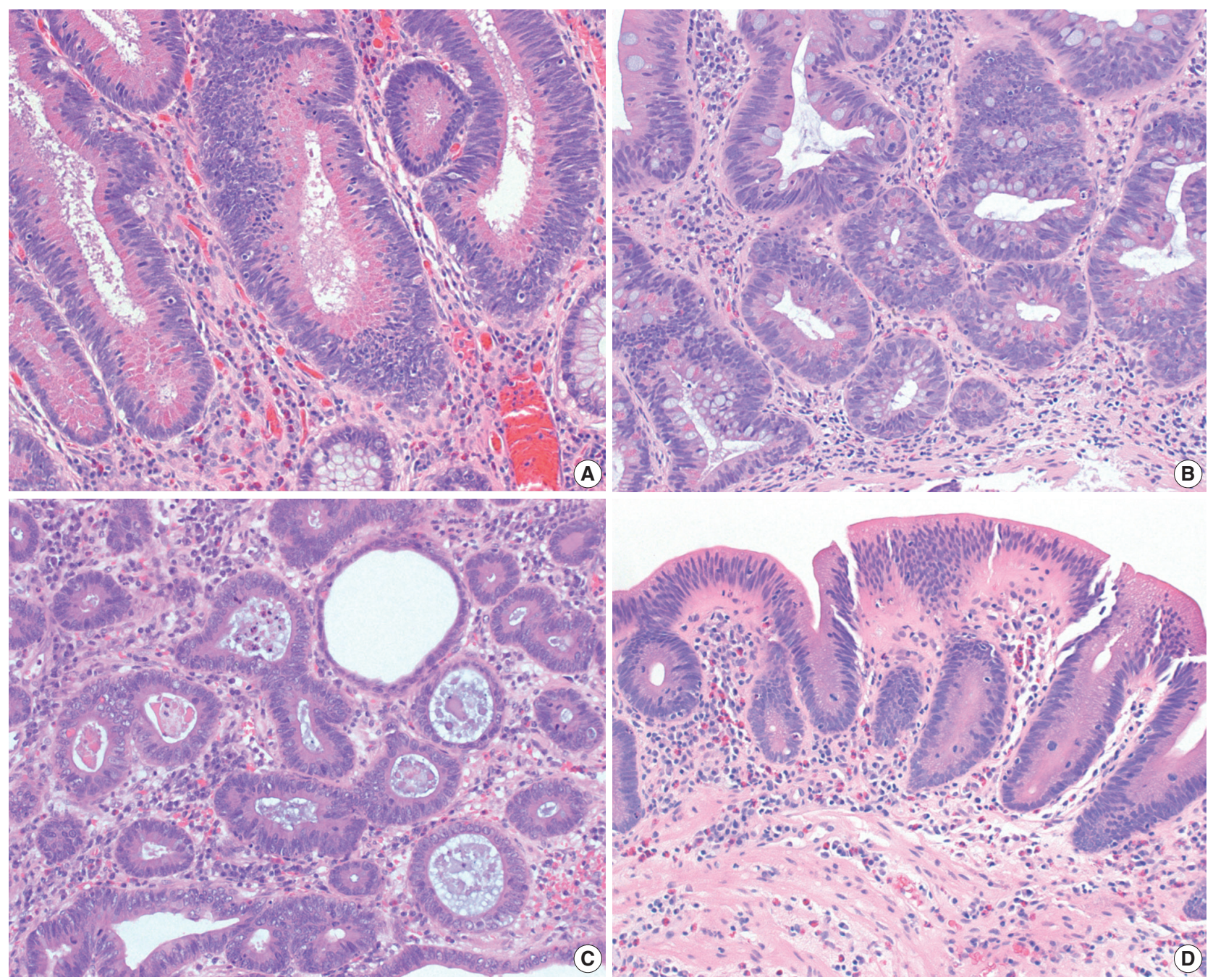

Fig. 4. Dysplasia with increased Paneth cell differentiation and goblet cell deficient dysplasia. (A, B) Dysplasia with increased Paneth cell differentiation shows increased Paneth cell differentiation involving multiple dysplastic crypts. (C, D) Goblet cell deficient dysplasia is defined by a complete or near-complete absence of goblet cells, leading to intensely bright eosinophilic cytoplasm. Eosinophilic luminal secretion is often seen in goblet cell deficient dysplasia (C).

lated with subsequent detection of $\mathrm{HGD}(\mathrm{n}=4,24 \%)$ or adenocarcinoma $(\mathrm{n}=6,35 \%)$ at the site of previous biopsy or in the same colonic segment within a mean follow-up time of 13 months (unpublished results). Also, low-grade goblet cell deficient dysplasia appears to have a higher rate of aneuploidy (25\%) than lowgrade conventional dysplasia (8\%) or sporadic adenomas (9\%) [38]. Furthermore, other investigators reported the high rates of TP53 (44\%), KRAS (22\%), and PIK3CA (56\%) mutations in goblet cell deficient dysplasia [47].

\section{Serrated dysplasia}

This category includes three distinct subtypes, including SSLlike dysplasia, TSA-like dysplasia, and serrated dysplasia NOS $[38,41,43]$. Serrated dysplastic lesions usually present as polyp- oid lesions with a mean size of $1.2 \mathrm{~cm}$ (Table 1) [38,56], and they are known to share similar clinicopathologic and molecular features with their sporadic counterparts [38,56-58]. For instance, while TSA-like dysplasia shows a propensity for the left colon, SSL-like dysplasia is more common in the right colon $[38,56,57]$. Ko et al. [56] also reported that low-grade serrated dysplasia in IBD patients often resembles sporadic TSA, occurs mainly in the left colon, and contains KRAS mutations (45\%). In addition, serrated dysplasia, in particular SSL-like dysplasia, usually lacks aneuploidy, suggesting that an alternative serrated pathway (without resulting in aneuploidy) may be responsible for the development of at least a subset of SSL-like and TSA-like dysplastic lesions [38,58].

Histologically, SSL-like dysplasia is characterized by distorted 


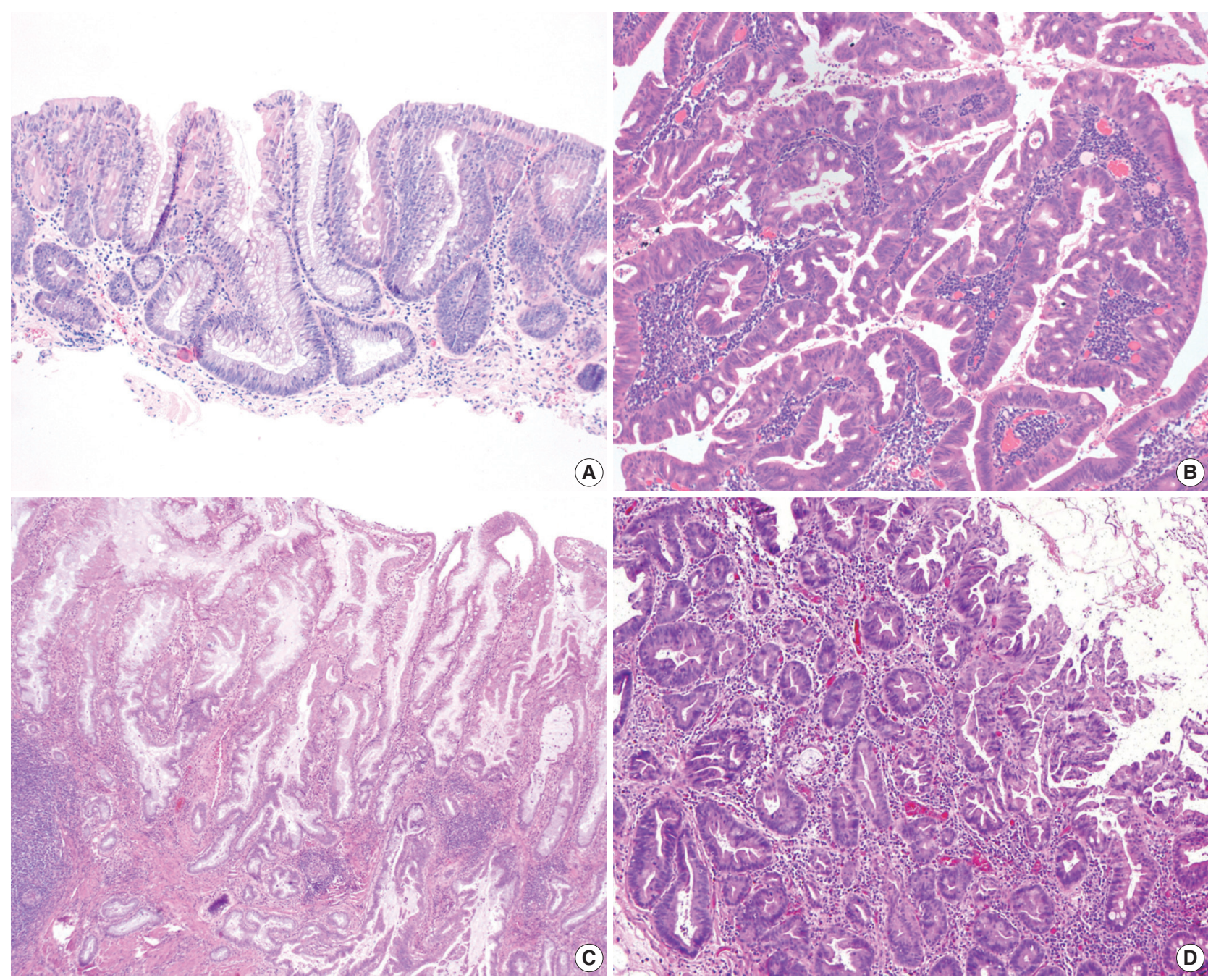

Fig. 5. Three subtypes of serrated dysplasia. (A) Sessile serrated lesion (SSL)-like dysplasia demonstrates a dilated L-shaped crypt at the interface with muscularis mucosa. (B) Traditional serrated adenoma (TSA)-like dysplasia shows villiform projections lined by elongated nuclei with intensely eosinophilic cytoplasm and ectopic crypts. (C) Serrated dysplasia not otherwise specified (NOS) shows a complex serrated architecture without definite features of SSL-like dysplasia or TSA-like dysplasia. (D) Another case of serrated dysplasia NOS mimics a hyperplastic polyp, but it shows full-thickness dysplasia with papillary or pseudopapillary changes on the surface epithelium.

serrated crypts with prominent basal crypt dilatation (i.e., dilated L- or inverted T-shaped crypts) at the interface with muscularis mucosa (Fig. 5A) [38,41,43]. TSA-like dysplasia most often demonstrates a tubulovillous/villous architecture lined by tall columnar cells with intensely eosinophilic cytoplasm and ectopic crypts (Fig. 5B) [38,41,43]. Serrated dysplasia NOS shows no definite features of SSL-like dysplasia or TSA-like dysplasia (Fig. 5C, D) $[38,41,43]$. Serrated dysplasia can co-exist with conventional dysplasia or another non-conventional subtype as a minor component, but to be classified as a specific serrated subtype, a serrated architecture should form the predominant feature representing $>50 \%$ of the lesion $[38,41]$.

Although the natural history of serrated dysplasia is not well defined in IBD patients, low-grade serrated dysplasia (which often resembles sporadic TSA) has been reported to have higher rates of advanced neoplasia $(17 \%$ within 10 years, $\mathrm{p}=.020)$ and prevalent neoplasia $(76 \%, \mathrm{p}<.001)$ than serrated lesions without dysplasia (0\% and $11 \%$, respectively) [56]. Its 10-year rate of advanced neoplasia (17\%) was similar to that of low-grade, non-serrated, conventional dysplasia (23\%) [56]. Overall, these findings suggest that although serrated lesions that lack dysplasia seem to pose little risk for advanced neoplasia, those with LGD are associated with increased rates of synchronous and metachronous neoplasia. However, their risk of developing advanced neoplasia is probably compatible to that of conventional dysplasia (Table 1). 


\section{CONCLUSION}

Non-conventional dysplasia in IBD has distinct clinicopathologic, molecular, and risk profiles compared with conventional dysplasia. Despite its low-grade morphology, non-conventional dysplasia, in particular hypermucinous, crypt cell, and goblet cell deficient dysplasias, has molecular alterations characteristic of conventional HGD (i.e., higher rates of aneuploidy and/or KRAS mutations) and appears to have a higher malignant potential than conventional dysplasia or sporadic adenomas. Therefore, it is important to recognize different non-conventional subtypes and recommend complete removal and/or careful follow-up. Also, a significant proportion of non-conventional dysplastic lesions present as invisible/flat lesions, suggesting that IBD patients may benefit from increased endoscopic surveillance with random biopsy sampling in addition to targeted biopsies.

\section{Ethics Statement}

Not applicable.

\section{ORCID}

Won-Tak Choi https://orcid.org/0000-0002-6892-5881

\section{Conflicts of Interest}

The author declares that he has no potential conflicts of interest.

\section{Funding Statement}

No funding to declare.

\section{References}

1. Ekbom A, Helmick C, Zack M, Adami HO. Ulcerative colitis and colorectal cancer: a population-based study. N Engl J Med 1990; 323: 1228-33.

2. Soderlund S, Brandt L, Lapidus A, et al. Decreasing time-trends of colorectal cancer in a large cohort of patients with inflammatory bowel disease. Gastroenterology 2009; 136: 1561-7.

3. Bernstein CN, Blanchard JF, Kliewer E, Wajda A. Cancer risk in patients with inflammatory bowel disease: a population-based study. Cancer 2001; 91: 854-62.

4. Jess T, Rungoe C, Peyrin-Biroulet L. Risk of colorectal cancer in patients with ulcerative colitis: a meta-analysis of population-based cohort studies. Clin Gastroenterol Hepatol 2012; 10: 639-45.

5. Ekbom A, Helmick C, Zack M, Adami HO. Increased risk of largebowel cancer in Crohn's disease with colonic involvement. Lancet 1990; 336: 357-9.

6. Eaden JA, Abrams KR, Mayberry JF. The risk of colorectal cancer in ulcerative colitis: a meta-analysis. Gut 2001; 48: 526-35.

7. Soetikno RM, Lin OS, Heidenreich PA, Young HS, Blackstone MO. Increased risk of colorectal neoplasia in patients with primary sclerosing cholangitis and ulcerative colitis: a meta-analysis. Gastrointest Endosc 2002; 56: 48-54.

8. Beaugerie L, Svrcek M, Seksik P, et al. Risk of colorectal high-grade dysplasia and cancer in a prospective observational cohort of pa- tients with inflammatory bowel disease. Gastroenterology 2013; 145: 166-75.

9. Lutgens MW, Oldenburg B, Siersema PD, et al. Colonoscopic surveillance improves survival after colorectal cancer diagnosis in inflammatory bowel disease. Br J Cancer 2009; 101: 1671-5.

10. Karlen P, Kornfeld D, Brostrom O, Lofberg R, Persson PG, Ekbom A. Is colonoscopic surveillance reducing colorectal cancer mortality in ulcerative colitis? A population based case control study. Gut 1998; 42: 711-4.

11. Eaden J, Abrams K, Ekbom A, Jackson E, Mayberry J. Colorectal cancer prevention in ulcerative colitis: a case-control study. Aliment Pharmacol Ther 2000; 14: 145-53.

12. Choi CH, Rutter MD, Askari A, et al. Forty-year analysis of colonoscopic surveillance program for neoplasia in ulcerative colitis: an updated overview. Am J Gastroenterol 2015; 110: 1022-34.

13. Laine L, Kaltenbach T, Barkun A, et al. SCENIC international consensus statement on surveillance and management of dysplasia in inflammatory bowel disease. Gastrointest Endosc 2015; 81: 489501.

14. Farraye FA, Odze RD, Eaden J, et al. AGA medical position statement on the diagnosis and management of colorectal neoplasia in inflammatory bowel disease. Gastroenterology 2010; 138: 738-45.

15. Leighton JA, Shen B, Baron TH, et al. ASGE guideline: endoscopy in the diagnosis and treatment of inflammatory bowel disease. Gastrointest Endosc 2006; 63: 558-65.

16. Odze RD. Adenomas and adenoma-like DALMs in chronic ulcerative colitis: a clinical, pathological, and molecular review. Am J Gastroenterol 1999; 94: 1746-50.

17. Rutter MD, Saunders BP, Wilkinson KH, Kamm MA, Williams $\mathrm{CB}$, Forbes A. Most dysplasia in ulcerative colitis is visible at colonoscopy. Gastrointest Endosc 2004; 60: 334-9.

18. Rubin DT, Rothe JA, Hetzel JT, Cohen RD, Hanauer SB. Are dysplasia and colorectal cancer endoscopically visible in patients with ulcerative colitis? Gastrointest Endosc 2007; 65: 998-1004.

19. Wanders LK, Dekker E, Pullens B, Bassett P, Travis SP, East JE. Cancer risk after resection of polypoid dysplasia in patients with longstanding ulcerative colitis: a meta-analysis. Clin Gastroenterol Hepatol 2014; 12: 756-64.

20. Blonski W, Kundu R, Furth EF, Lewis J, Aberra F, Lichtenstein GR. High-grade dysplastic adenoma-like mass lesions are not an indication for colectomy in patients with ulcerative colitis. Scand J Gastroenterol 2008; 43: 817-20.

21. Odze RD, Farraye FA, Hecht JL, Hornick JL. Long-term follow-up after polypectomy treatment for adenoma-like dysplastic lesions in ulcerative colitis. Clin Gastroenterol Hepatol 2004; 2: 534-41.

22. Kisiel JB, Loftus EV Jr, Harmsen WS, Zinsmeister AR, Sandborn WJ. Outcome of sporadic adenomas and adenoma-like dysplasia in patients with ulcerative colitis undergoing polypectomy. Inflamm Bowel Dis 2012; 18: 226-35.

23. Connell WR, Lennard-Jones JE, Williams CB, Talbot IC, Price AB, Wilkinson KH. Factors affecting the outcome of endoscopic surveillance for cancer in ulcerative colitis. Gastroenterology 1994; 107: 934-44.

24. Friedman S, Rubin PH, Bodian C, Goldstein E, Harpaz N, Present DH. Screening and surveillance colonoscopy in chronic Crohn's colitis. Gastroenterology 2001; 120: 820-6.

25. Hata K, Watanabe T, Kazama S, et al. Earlier surveillance colonoscopy programme improves survival in patients with ulcerative coli- 
tis associated colorectal cancer: results of a 23-year surveillance programme in the Japanese population. Br J Cancer 2003; 89: 1232-6.

26. Bernstein CN, Shanahan F, Weinstein WM. Are we telling patients the truth about surveillance colonoscopy in ulcerative colitis? Lancet 1994; 343: 71-4.

27. Thomas T, Abrams KA, Robinson RJ, Mayberry JF. Meta-analysis: cancer risk of low-grade dysplasia in chronic ulcerative colitis. Aliment Pharmacol Ther 2007; 25: 657-68.

28. Jess T, Loftus EV Jr, Velayos FS, et al. Incidence and prognosis of colorectal dysplasia in inflammatory bowel disease: a populationbased study from Olmsted County, Minnesota. Inflamm Bowel Dis 2006; 12: 669-76.

29. Ullman T, Croog V, Harpaz N, Sachar D, Itzkowitz S. Progression of flat low-grade dysplasia to advanced neoplasia in patients with ulcerative colitis. Gastroenterology 2003; 125: 1311-9.

30. Ullman TA, Loftus EV Jr, Kakar S, Burgart LJ, Sandborn WJ, Tremaine WJ. The fate of low grade dysplasia in ulcerative colitis. Am J Gastroenterol 2002; 97: 922-7.

31. van Schaik FD, ten Kate FJ, Offerhaus GJ, et al. Misclassification of dysplasia in patients with inflammatory bowel disease: consequences for progression rates to advanced neoplasia. Inflamm Bowel Dis 2011; 17: 1108-16.

32. Befrits R, Ljung T, Jaramillo E, Rubio C. Low-grade dysplasia in extensive, long-standing inflammatory bowel disease: a follow-up study. Dis Colon Rectum 2002; 45: 615-20.

33. Venkatesh PG, Jegadeesan R, Gutierrez NG, Sanaka MR, Navaneethan U. Natural history of low grade dysplasia in patients with primary sclerosing cholangitis and ulcerative colitis. J Crohns Colitis 2013; 7: 968-73.

34. Pekow JR, Hetzel JT, Rothe JA, et al. Outcome after surveillance of low-grade and indefinite dysplasia in patients with ulcerative colitis. Inflamm Bowel Dis 2010; 16: 1352-6.

35. Zisman TL, Bronner MP, Rulyak S, et al. Prospective study of the progression of low-grade dysplasia in ulcerative colitis using current cancer surveillance guidelines. Inflamm Bowel Dis 2012; 18: 2240-6.

36. Navaneethan U, Jegadeesan R, Gutierrez NG, et al. Progression of low-grade dysplasia to advanced neoplasia based on the location and morphology of dysplasia in ulcerative colitis patients with extensive colitis under colonoscopic surveillance. J Crohns Colitis 2013; 7: e684-91.

37. Tsai JH, Rabinovitch PS, Huang D, et al. Association of aneuploidy and flat dysplasia with development of high-grade dysplasia or colorectal cancer in patients with inflammatory bowel disease. Gastroenterology 2017; 153: 1492-5.

38. Lee H, Rabinovitch PS, Mattis AN, Lauwers GY, Choi WT. Nonconventional dysplasia in inflammatory bowel disease is more frequently associated with advanced neoplasia and aneuploidy than conventional dysplasia. Histopathology 2020 Nov 5 [Epub]. https:// doi.org/10.1111/his.14298.

39. Wanders LK, Cordes M, Voorham Q, et al. IBD-associated dysplastic lesions show more chromosomal instability than sporadic adenomas. Inflamm Bowel Dis 2020; 26: 167-80.

40. Riddell RH, Goldman H, Ransohoff DF, et al. Dysplasia in inflammatory bowel disease: standardized classification with provisional clinical applications. Hum Pathol 1983; 14: 931-68.

41. Choi WT, Yozu M, Miller GC, et al. Nonconventional dysplasia in patients with inflammatory bowel disease and colorectal carcino- ma: a multicenter clinicopathologic study. Mod Pathol 2020; 33: 933-43.

42. Wen KW, Umetsu SE, Goldblum JR, et al. DNA flow cytometric and interobserver study of crypt cell atypia in inflammatory bowel disease. Histopathology 2019; 75: 578-88.

43. Pereira D, Kovari B, Brown I, et al. Non-conventional dysplasias of the tubular gut: a review and illustration of their histomorphological spectrum. Histopathology 2020 Oct 30 [Epub]. https://doi. org/10.1111/his.14294.

44. Watanabe T, Ajioka Y, Mitsuyama K, et al. Comparison of targeted vs random biopsies for surveillance of ulcerative colitis-associated colorectal cancer. Gastroenterology 2016; 151: 1122-30.

45. Andersen SN, Lovig T, Clausen OP, Bakka A, Fausa O, Rognum TO. Villous, hypermucinous mucosa in long standing ulcerative colitis shows high frequency of K-ras mutations. Gut 1999; 45: 686-92.

46. Maltzman T, Knoll K, Martinez ME, et al. Ki-ras proto-oncogene mutations in sporadic colorectal adenomas: relationship to histologic and clinical characteristics. Gastroenterology 2001; 121: 302-9.

47. Gui X, Kobel M, Ferraz JG, et al. Histological and molecular diversity and heterogeneity of precancerous lesions associated with inflammatory bowel diseases. J Clin Pathol 2020; 73: 391-402.

48. Vogelstein B, Fearon ER, Hamilton SR, et al. Genetic alterations during colorectal-tumor development. N Engl J Med 1988; 319: 525-32.

49. Ried T, Knutzen R, Steinbeck R, et al. Comparative genomic hybridization reveals a specific pattern of chromosomal gains and losses during the genesis of colorectal tumors. Genes Chromosomes Cancer 1996; 15: 234-45.

50. Meijer GA, Hermsen MA, Baak JP, et al. Progression from colorectal adenoma to carcinoma is associated with non-random chromosomal gains as detected by comparative genomic hybridisation. J Clin Pathol 1998; 51: 901-9.

51. Lomo LC, Blount PL, Sanchez CA, et al. Crypt dysplasia with surface maturation: a clinical, pathologic, and molecular study of a Barrett's esophagus cohort. Am J Surg Pathol 2006; 30: 423-35.

52. Joo M, Shahsafaei A, Odze RD. Paneth cell differentiation in colonic epithelial neoplasms: evidence for the role of the Apc/beta-catenin/ Tcf pathway. Hum Pathol 2009; 40: 872-80.

53. Mahon M, Xu J, Yi X, Liu X, Gao N, Zhang L. Paneth cell in adenomas of the distal colorectum is inversely associated with synchronous advanced adenoma and carcinoma. Sci Rep 2016; 6: 26129.

54. Bansal M, Fenoglio CM, Robboy SJ, King DW. Are metaplasias in colorectal adenomas truly metaplasias? Am J Pathol 1984; 115: 253-65.

55. Pai RK, Rybicki LA, Goldblum JR, Shen B, Xiao SY, Liu X. Paneth cells in colonic adenomas: association with male sex and adenoma burden. Am J Surg Pathol 2013; 37: 98-103.

56. Ko HM, Harpaz N, McBride RB, et al. Serrated colorectal polyps in inflammatory bowel disease. Mod Pathol 2015; 28: 1584-93.

57. Yang C, Tarabishy Y, Dassopoulos T, Nalbantoglu I. Clinical, histologic, and immunophenotypic features of serrated polyps in patients with inflammatory bowel disease. Gastroenterology Res 2018; 11 : 355-60.

58. Choi WT, Wen KW, Rabinovitch PS, Huang D, Mattis AN, Gill RM. DNA content analysis of colorectal serrated lesions detects an aneuploid subset of inflammatory bowel disease-associated serrated epithelial change and traditional serrated adenomas. Histopathology 2018; 73: 464-72. 